\title{
Etiopathology of Hoarseness of Voice: A Clinical Study
}

\author{
${ }^{1}$ Syamji V Rao, ${ }^{2}$ Varanasi S Sharma, ${ }^{3} \mathrm{MV}$ Subba Rao, ${ }^{4} \mathrm{GS}$ Keerthi, ${ }^{5}$ Sheeba I Deta, ${ }^{6}$ Pravin T Seepana, ${ }^{7}$ Vijay Kumar
}

\begin{abstract}
Aim: Hoarseness of voice is generally due to change in quality of voice. The etiology of hoarseness of voice varies from benign conditions to malignant disease, hence should not be ignored. All cases of hoarseness of voice persisting for more than 3 weeks should be investigated for the underlying disease. It may indicate either malignancy of larynx or silent bronchogenic carcinoma. A retrospective study of cases of hoarseness of voice was done in MediCiti Institute of Medical Sciences for a period of 5 years. The etiopathological factors, age and duration of presentation, and type of condition were analyzed to arrive at different etiopathological conditions responsible at different age groups.
\end{abstract}

Keywords: Hoarseness of voice, Etiology, Predisposing factors.

How to cite this article: Rao SV, Sharma VS, Rao MVS, Keerthi GS, Deta SI, Seepana PT, Kumar V. Etiopathology of Hoarseness of Voice: A Clinical Study. Int J Phonosurg Laryngol 2016;6(2):64-67.

\section{Source of support: Nil}

Conflict of interest: None

\section{INTRODUCTION}

Hoarseness of voice is one of the commonest symptoms in otolaryngology outpatient clinic. It may be due to various diseases ranging from inflammatory conditions neoplasm, which may be benign or malignant - to neurological conditions. Hoarseness of voice is described as change in normal voice quality. It may indicate breathiness, roughness, voice breaks, or abnormal changes in the pitch. Dysphonia is used to describe abnormal voice quality. Complaints of hoarseness of voice may indicate sometimes serious underlying disease and should not be ignored.

\section{MATERIALS AND METHODS}

A retrospective study by simple random sampling of 100 cases of hoarseness of voice out of 140 cases attending ear, nose, and throat (ENT) outpatient department (OPD)

${ }^{1}$ Professor, ${ }^{2}$ Assistant Professor, ${ }^{3}$ Professor and Head, $, 4,6,7$ Junior Resident, ${ }^{5}$ Speech and Language Pathologist

${ }^{1-7}$ Department of ENT, MediCiti Institute of Medical Sciences and Hospital, Hyderabad, Telangana, India

Corresponding Author: Varanasi S Sharma, Assistant Professor Department of ENT, MediCiti Institute of Medical Sciences and Hospital, Hyderabad, Telangana, India, Phone: +919391005580 e-mail: sharmavaranasi.15@gmail.com was done at a tertiary care hospital for a period of 5 years, i.e., from January 2011 to December 2015. One hundred patients were selected based on patient cooperation and consent for the study. Age, sex incidence, etiological factors, and type of condition is evaluated and analyzed. All the cases underwent detailed history, including predisposing causes like occupation, addictions, thorough clinical evaluation, and video endoscopy. Results obtained were further analyzed in terms of age, occupation, addictions, and type of clinical condition.

\section{RESULTS}

The incidence of hoarseness of voice was around $0.51 \%$ between January 2011 and December 2015. A total of 27,000 cases attended at ENT OPD during the above period, and 100 patients presented with hoarseness of voice.

\section{Age Incidence}

A majority of the patients were seen in the age group of 21 to $50(68 \%)$ - and most common in the 4 th decade - and in the age group of 60 to 70 years (Table 1 ).

\section{Sex Incidence}

Hoarseness of voice is commonly seen in males, and male-to-female ratio is around 2:1.

\section{Cause}

The commonest cause for hoarseness of voice in our series is laryngitis (36\%), followed by vocal nodule (24\%), and the third commonest cause is neurological (16\%).

\section{Occupation}

Hoarseness of voice is more commonly seen in laborers $(36 \%)$, homemakers $(20 \%)$, farmers $(18 \%)$, teachers and singers $(16 \%)$, hawkers $(9 \%)$, and students $(1 \%)$.

Table 1: Age and sex distribution of patients of hoarseness of voice

\begin{tabular}{lllll}
\hline Sl. no. & Age group & Male & Female & No. of cases \\
\hline 1 & $1-10$ & 2 & - & 2 \\
2 & $11-20$ & 8 & 1 & 9 \\
3 & $21-30$ & 7 & 9 & 16 \\
4 & $31-40$ & 21 & 13 & 34 \\
5 & $41-50$ & 12 & 6 & 18 \\
6 & $51-60$ & 11 & 2 & 13 \\
7 & $>60$ & 7 & 1 & 8 \\
\hline
\end{tabular}


Etiopathology of Hoarseness of Voice: A Clinical Study

Table 2: Incidence, age, sex distribution, and occupation of hoarseness of voice

\begin{tabular}{llllll}
\hline Etiology & Incidence (\%) & Age group (decade) & Sex (male:female) & Occupation & Distribution \\
\hline Laryngitis & 36 & $3,4,5$ & $1: 1$ & Laborers, homemakers & Rural \\
Vocal nodule & 24 & $2,3,4$ & $1: 1.5$ & Teachers, singers, homemakers & Urban \\
Neurological & 16 & $2,3,4$ & $2: 1$ & Laborers, farmers & Rural \\
Neoplastic & 13 & $4,6,7$ & Males & Laborers & Rural \\
Vocal cord polyp & 8 & 3 & $2: 1$ & Laborers, hawkers & Urban and rural \\
Foreign bodies & 1 & 2 & $1: 0$ & Student & Urban \\
Aryepiglottic fold cyst & 1 & 5 & $1: 0$ & Laborer & Rural \\
Puberphonia & 1 & 2 & $1: 0$ & Student & Rural \\
\hline
\end{tabular}

The incidence, age, sex distribution, and occupation of subjects with hoarseness of voice are shown in Table 2 .

\section{Rural/Urban Distribution}

Hoarseness of voice is predominantly seen in rural areas, roughly around $70 \%$. Only $30 \%$ are from urban area, and rural-to-urban ratio is 2.3:1.

\section{Habits and Addiction}

In our study, history of smoking is seen in $32 \%$, tobacco chewing in $11 \%$, and alcohol consumption in $21 \%$ of cases. Broek ${ }^{1}$ reported smoking as one of the important predisposing factors for hoarseness of voice. Parikh found smoking in $20 \%$ of patients. Shaw ${ }^{2}$ mentioned that chronic irritation of mucosa by smoking, intake of alcohol, and tobacco chewing are responsible for hoarseness of voice. Carcinoma larynx is extremely rare in nonsmokers, and risk increases with the intensity of smoking. Risk of carcinoma in smokers increases 4 to 40 times as compared to nonsmokers. ${ }^{3}$ In our study, the incidence of smoking in neoplasms is $84 \%$. Intake of alcohol increases the risk of laryngeal cancer, by 3 to 4 times. Thompson et $\mathrm{al}^{4}$ reported about $47.1 \%$ of patients taking alcohol with tobacco intake. Smoking along with alcohol intake is seen in $69.2 \%$ of cases producing carcinoma of larynx in our study. Figure 1 shows the carcinoma of larynx.

\section{Vocal Abuse}

In our series, vocal abuse was seen in $53 \%$ of patients. Rosen et $\mathrm{al}^{5}$ in 1988 , found vocal abuse as one of the

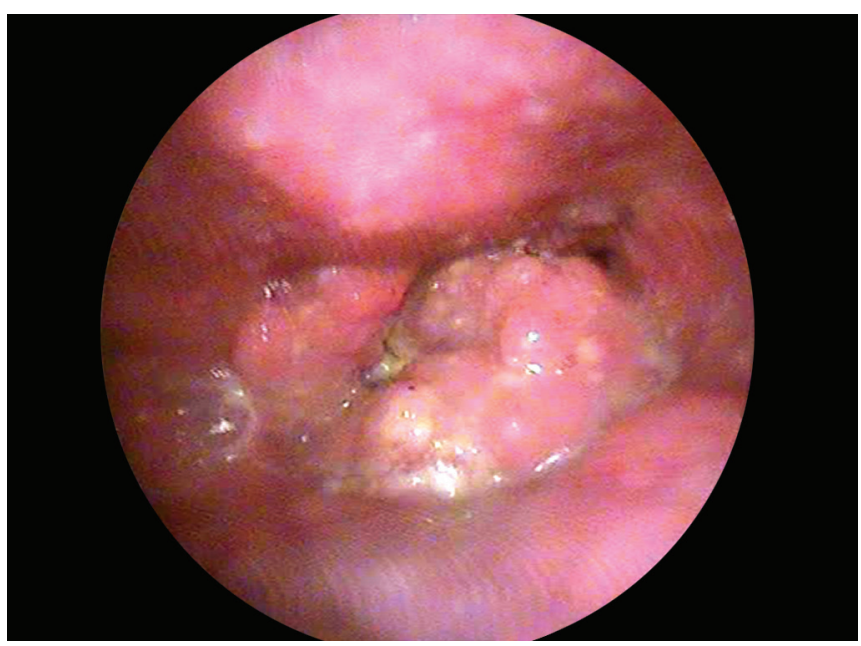

Fig. 1: Carcinoma of larynx

most common cause of hoarseness of Voice. Kaluskar, ${ }^{6}$ Mehta $^{7}$ and Parikh ${ }^{8}$ gave higher incidence, i.e., 62.5, 49, $56 \%$ respectively.

Duration of hoarseness of voice: Ranged from 1 day to 5 years. Fifty percent of patients presented within 6 months. The predisposing factors of hoarseness of voice mentioned above in correspondence to those observed in study group are shown in Table 3.

\section{Presentation}

Apart from the change of voice (93\%), other associated symptoms are vocal fatigue (12\%), painful vocalization $(8 \%)$, breathy voice $(6 \%)$, swelling in the neck $(13 \%)$, recurrent upper respiratory tract infection (URTI) $(7 \%)$, cough $(4 \%)$. These symptoms of hoarseness of voice in

Table 3: Etiology and predisposing factors in hoarseness of voice

\begin{tabular}{|c|c|c|c|c|c|c|c|c|c|c|c|}
\hline \multirow[b]{2}{*}{ Etiology } & \multicolumn{2}{|c|}{ Vocal abuse } & \multicolumn{2}{|c|}{ Smoking } & \multicolumn{2}{|c|}{ Alcohol } & \multicolumn{2}{|c|}{ Tobacco chewing } & \multicolumn{2}{|c|}{ Oral sepsis } & \multirow{2}{*}{$\begin{array}{l}\text { Predisposing } \\
\text { factors (\%) }\end{array}$} \\
\hline & Yes & No & Yes & No & Yes & No & Yes & No & Yes & No & \\
\hline Laryngitis & 20 & 16 & 10 & 26 & 9 & 27 & 8 & 28 & 18 & 18 & 36 \\
\hline Vocal nodule & 21 & 5 & 16 & 10 & 6 & 20 & 1 & 25 & 1 & 25 & 26 \\
\hline Vocal cord polyp & 6 & 2 & 4 & 4 & 3 & 5 & 2 & 6 & 1 & 7 & 08 \\
\hline Neoplastic & 5 & 7 & 11 & 1 & 9 & 3 & 9 & 3 & 5 & 7 & 12 \\
\hline Neurological & 1 & 15 & 6 & 10 & 8 & 8 & 4 & 12 & 1 & 15 & 16 \\
\hline Foreign bodies & 0 & 1 & 0 & 1 & 1 & 0 & 0 & 1 & 0 & 1 & 01 \\
\hline Cysts & 1 & 0 & 1 & 0 & 1 & 0 & 0 & 0 & 1 & 0 & 1 \\
\hline
\end{tabular}




\begin{tabular}{ll}
\multicolumn{2}{c}{ Table 4: Presenting symptoms in hoarseness of voice } \\
\hline & $\begin{array}{l}\text { Percentage of } \\
\text { occurrence }\end{array}$ \\
\hline Presenting symptoms & 93 \\
Hoarseness of voice & 12 \\
Vocal fatigue & 8 \\
Painful vocalization & 6 \\
Breathy voice & 13 \\
Swelling in the neck & 7 \\
Recurrent URTI & 4 \\
Cough & \\
\hline
\end{tabular}

the closed group corresponding to the percentage of occurrence are shown in Table 4.

\section{Septic Focus}

Obvious dental infection, sinusitis, and tonsillitis are seen in $40 \%$ of patients. Mehta ${ }^{7}$ and Parikh $^{8}$ reported incidence of septic foci in $43 \%$ of their patients, whereas Kaluskar ${ }^{6}$ has reported higher incidence of septic foci $(59 \%)$ in patients of hoarseness of voice.

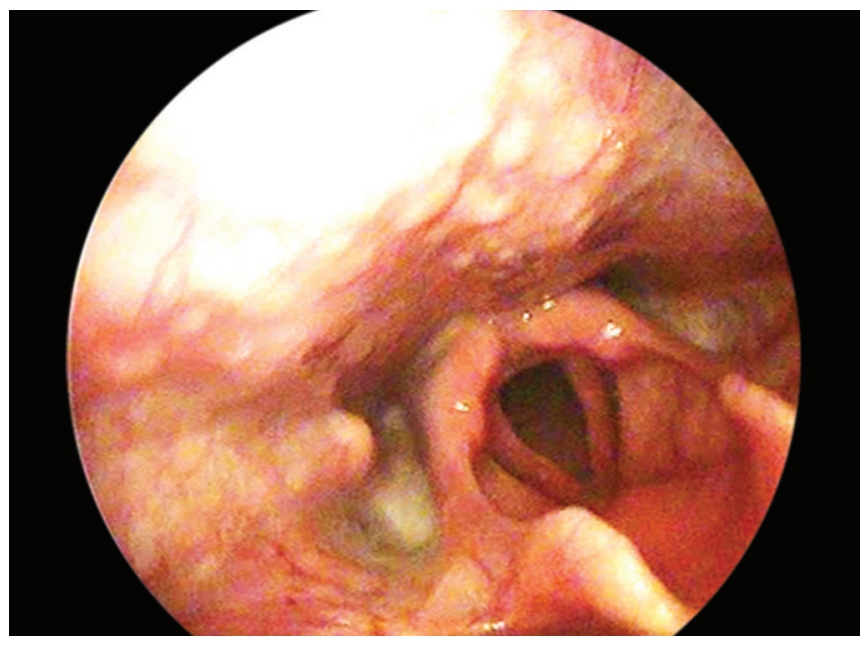

Fig. 2: Chronic laryngitis

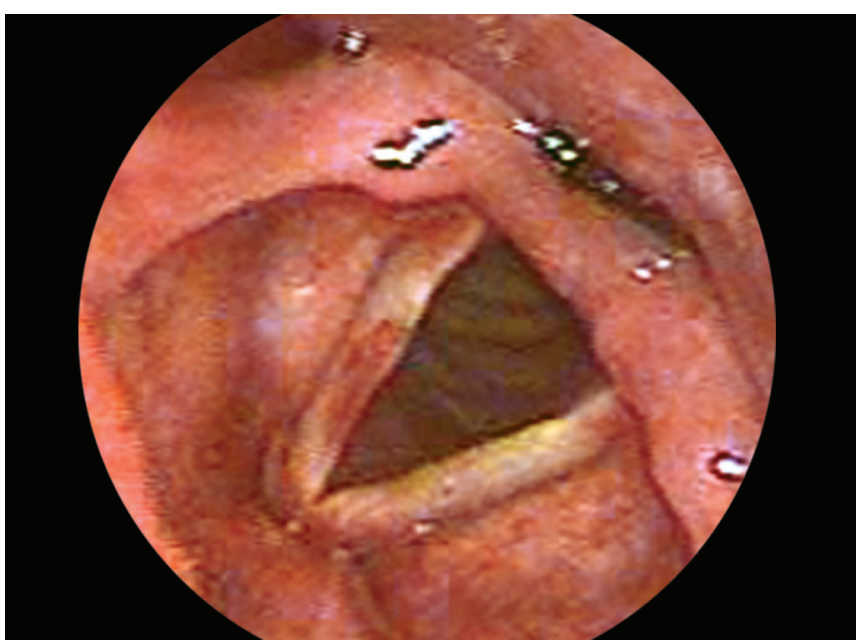

Fig. 4: Foreign body with laryngitis

\section{Videolaryngoscopy (VLS) Findings and Diagnosis}

Laryngitis was seen in $36 \%$ of patients with finding of congestion of vocal cord in 31\%. Thickening and leukoplakia was seen in $5 \%$ cases. Vocal nodule was seen in $26 \%$ of cases. Vocal cord palsy was seen in $16 \%$ of patients. Neoplasm was seen in $12 \%$, of which $10 \%$ are malignant and $2 \%$ are benign tumors (palillomas and fibroangiomas). Vocal cord polyp was seen in $8 \%$. Foreign body producing hoarseness of voice was seen in $1 \%$. Cysts causing hoarseness of voice was seen in $1 \%$.

Chronic laryngitis (Fig. 2), vocal cord palsy (Fig. 3), foreign body (Fig. 4), and aryepiglottic cyst (Fig. 5) cause hoarseness of voice.

\section{DISCUSSION}

In our study, incidence of hoarseness of voice in total OPD is $0.51 \%$. The incidence of different causes leading to hoarseness of voice is seen in Table 2. The leading cause for hoarseness of voice is acute laryngitis is $35 \%$, followed

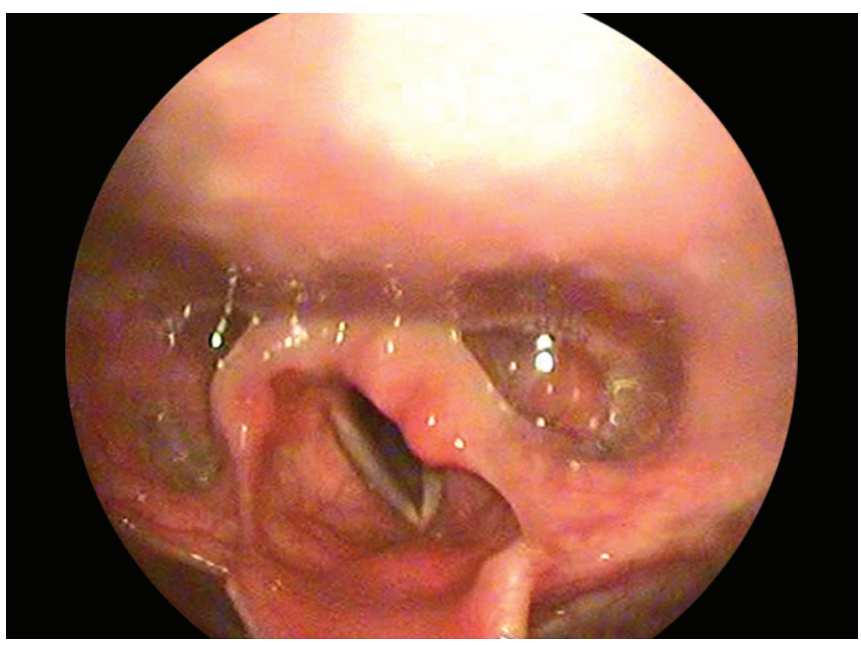

Fig. 3: Left vocal cord palsy

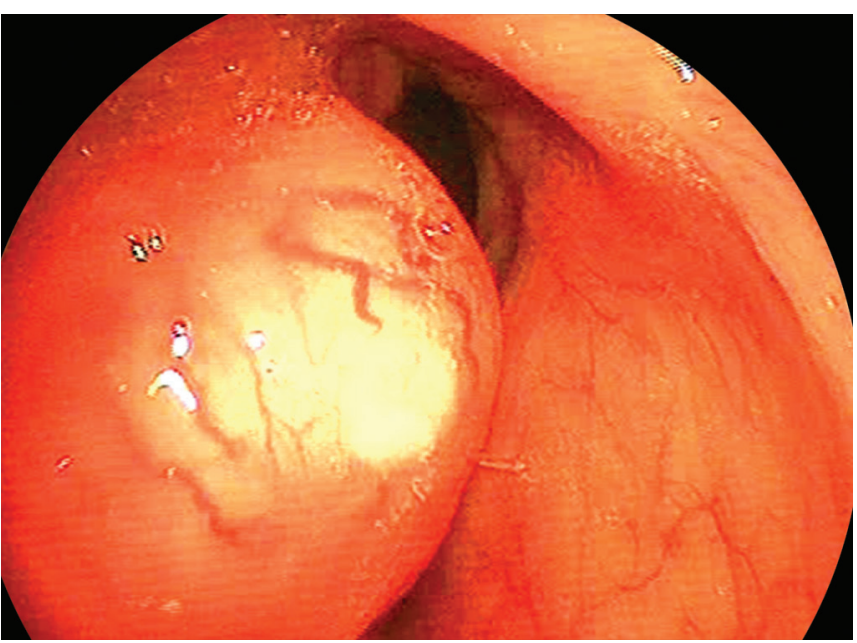

Fig. 5: Ary-epiglottic fold cyst 
by vocal nodule $(26 \%)$. The commonest age incidence of hoarseness of voice is the 4th decade of life, and maleto-female ratio is $2.3: 1$, indicating male predominance. Some common etiological factors are dental infection and addiction to tobacco. Mehta ${ }^{7}$ and Hirschberg et $\mathrm{al}^{9}$ reported higher incidence in urban population. In our study, rural-to-urban ratio is 2:1. More commonly, in rural areas, farmers, laborers, and those who are habituated to tobacco are presenting with hoarseness. The duration of hoarseness of voice ranged from 1 day to 5 years, while $50 \%$ of patients presented within 6 months. Chopra and Kapoor ${ }^{10}$ noted that $68.65 \%$ of patients with duration of hoarseness of voice of less than one year. Septic focus in oral cavity is seen in $40 \%$ of cases. In the present study, hoarseness of voice is the presenting symptom in $93 \%$ along with vocal fatigue in $12 \%$ of cases. Hansa et $\mathrm{al}^{10}$ have also shown hoarseness as a major complaint (95.61\%). Mehta $^{7}$ and Baitha et $\mathrm{al}^{8,11}$ have done similar studies. Associated symptoms are painful vocalization $(8 \%)$, breathy voice $(6 \%)$, swelling in the neck $(13 \%)$, recurrent URTI $(7 \%)$, and cough $(4 \%)$. Among the predisposing causes, smoking is seen in $47 \%$, alcohol intake in $39 \%$, chewing tobacco in $24 \%$, and vocal abuse in $53 \%$. In a study conducted by Hansa et al, ${ }^{10}$ smoking was observed in $43 \%$ of cases, vocal abuse in $31 \%$, alcohol intake in $29.48 \%$, and tobacco chewing in $29.48 \%$. In our study, high incidence of vocal abuse is seen (53\%) due to occupations like laborers, hawkers, homemakers, singers, and teachers.

\section{CONCLUSION}

The incidence of hoarseness of voice in OPD is $0.17 \%$. Male-to-female ratio for this incidence is 2.3:1. Hoarseness of voice is commonly noted in 4th decade of life. The commonest cause of hoarseness is chronic laryngitis followed by vocal nodule. The commonest etiological factors responsible for hoarseness of voice are occupation, smoking, tobacco chewing, and oral sepsis. In presenting symptoms, hoarseness of voice is seen in $93 \%$ of cases, along with vocal fatigue $(12 \%)$. Other common causes of hoarseness of voice are laryngitis (36\%), vocal nodule (26\%), vocal cord palsy $(16 \%)$.

\section{CLINICAL SIGNIFICANCE}

The etiopathological study of hoarseness of voice is done to know various etiological factors responsible for hoarseness of voice and the disease caused by it. Finding out the role of addictions like alcohol, smoking, tobacco chewing highlights the need to caution the public about the dangerous consequences like malignancies.

\section{REFERENCES}

1. Broek, P. Acute and chronic laryngitis. In: Hibbert, J., editor. Scott Brown's otolaryngology. 6th ed. Oxford: Butterworth Hienemann; 1997. 5/5/1-20.

2. Shaw H. Tumours of larynx. In: Ballantyne, J.; Groves, J., editors. Scott - Brown; diseases of ear, nose and throat. 4th ed. London: Butterworths; 1979. p. 421-508.

3. Cowles SR. Cancer of larynx occupational and environmental associations. South Med J 1983 Jul;76(6):894-898.

4. Thompson LD, Wenig BM, Heffner DK, Gnepp DR. Exophytic and papillary squamous cell carcinomas of the larynx. A clinic pathalogic series of 104 cases. Otolaryngol Head Neck Surg 1999 May;120(5):718-724.

5. Rosen CA, Anderson D, Murray T. Evaluating hoarseness keeping your patients voice healthy. Am Fam Physician 1998;57(11):2775-2782.

6. Kaluskar. Study of Hoarseness of Voice: a thesis submitted for Master of Surgery (Otorhinolaryngology), Gujarat University; 1971.

7. Mehta AS. An etiological study of hoarseness of voice. A thesis submitted for master of surgery (Otorhinolaryngology), Gujarat University, 1985.

8. Parikh NP. Aetiology study of 100 cases of hoarseness of voice. Indian J Otolaryngol Head Neck Surg 1991 Jun;43(2): 71-73.

9. Hirschberg J, Dejonckere PH, Hirano M, Mori K, SchultzCoulon HJ, Vrticka K. Voice disorders in children. Int J Pediatr Otorhinolaryngol 1995 Jun;32(suppl):S109-S125.

10. Chopra H, Kapoor M. Study of benign glottic lesions undergoing microlaryngeal surgery. Indian J Otolaryngol Head Neck Surg 1997 Jul;49(3):276-279.

11. Baitha S, Raizada RM, Kennedy Singh AK, Puttewar MP, Chaturvedi VN. Clinical profile of hoarseness of voice. Indian J Otolaryngol Head Neck Surg 2002 Jan;54(1):14-18.

12. Hansa B, et al. Hoarseness of Voice: a retrospective study of 251 cases. Int J Phonosurg Laryngol. Jan-Jun 2011;1(1):21-27. 